\title{
Microwave Assisted Synthesis of Thiocarbamoylpyrazoles and Application as an Alternative Latent Fingermark Developers
}

\author{
Bruno N. da Rosa, ${ }^{a}$ Dalila Venzke, ${ }^{a}$ Taís Poletti, ${ }^{a}$ Nathalia P. K. de Lima, ${ }^{a}$ \\ Jeanifer T. Camacho, ${ }^{a}$ Kristiane C. Mariotti, ${ }^{b}$ Marco A. Z. dos Santos, ${ }^{a}$ Lucas Pizzuti, ${ }^{\circ}$ c \\ Neftalí L. V. Carreño ${ }^{d}$ and Claudio M. P. Pereira ${ }^{\circledR *, a}$ \\ ${ }^{a}$ Grupo de Pesquisa Bioforense, Centro de Ciências Químicas, Farmacêuticas e de Alimentos, \\ Universidade Federal de Pelotas, 96010-900 Pelotas-RS, Brazil \\ ${ }^{b}$ Grupo de Identificação, Polícia Federal do Brasil, 90610-093 Porto Alegre-RS, Brazil \\ ${ }^{c}$ Grupo de Pesquisa de Síntese e Caracterização Molecular, Instituto de Química, \\ Universidade Federal do Mato Grosso do Sul, 79077-460 Campo Grande-MS, Brazil \\ ${ }^{d}$ Grupo de Pesquisa Novonano, Programa de Pós Graduação em Ciência e Engenharia de Materiais, \\ Centro de Desenvolvimento Tecnológico, Universidade Federal de Pelotas, \\ 96010-000 Pelotas-RS, Brazil
}

\begin{abstract}
Fingerprints are unique to each individual, contributing to human identification in forensic cases. The powder technique being widely used is considered one of the most important in latent fingermarks analysis. In this sense, the present work aimed to synthesize 1-thiocarbamoyl-4,5dihydro- $1 H$-pyrazoles and apply them as powder agents to develop latent fingermarks. The compounds were prepared from an effective and green synthesis via the condensation of chalcones with thiosemicarbazide in ethanol under microwave irradiation. Pyrazoles were tested and compared with a standard white powder (Sirchie ${ }^{\circledR}$ ) on glass surfaces using sebaceous and natural fingermarks so that molecule $\mathbf{2} \mathbf{c}$ has been shown to be more promising providing image clarity. The derivatives of pyrazoles were promising as an alternative latent fingermark, presenting high quality images for fingermarks, proving to be a great tool for forensic sciences.
\end{abstract}

Keywords: pyrazole, dusting powder, latent fingermark, forensic chemistry

\section{Introduction}

Pyrazole and derivatives are interesting heterocyclic compounds since they show a wide range of pharmacological and biological properties including antioxidant, antitumor, antimicrobial, analgesic and anti-inflamatory. ${ }^{1-4}$ In general, the activities are provided because of the presence of the $\mathrm{N}-\mathrm{N}$ bonds in the pyrazole ring. ${ }^{5}$ Microwave assisted organic synthesis highlights key advances in the development of organic chemistry. Its efficiency in accelerating reaction rates has been emulated in several fields of organic synthesis. ${ }^{6-8}$ This can improve the yield and purity of the final compounds in short reaction times through the precise control of parameters such as power irradiation, pressure and temperature. ${ }^{9,10}$

*e-mail: lahbbioufpel@gmail.com
The fingermarks when detected at crime scenes are considered as circumstantial evidence in forensic investigations and criminal justice. ${ }^{11}$ Such importance is due to the uniqueness in ridge pattern for each individual and thus are unique and vital for the identification and/or involvement of a suspect. ${ }^{12}$ When found in the latent form, for visualization to be possible, it is necessary that some substances react chemically or physically with the compounds present in the fingermark. ${ }^{13}$ In this context, heterocyclic compounds have been contributing to papiloscopy for the improvement of new fingermark developers. For example, phenanthro imidazole and benzazoles have been used as new fluorescent powder for the development of latent fingermarks; and 1,2-indanedione and ninhydrins derivatives as novel reagents for detection of amino acids in latent fingermarks. ${ }^{14-18}$

Motivated by the importance of forensic chemistry, and in continuation of our research efforts, ${ }^{19-21}$ we have tried to 
highlight aspects reported on the chemistry and forensic application of pyrazole nucleous. The aim of this work was to synthesize a series of 1-thiocarbamoyl-3,5-diaryl4,5-dihydro- $1 H$-pyrazoles under microwave irradiation in order to applied them as novel white powders for the development of latent fingermarks.

\section{Experimental}

\section{Apparatus and analysis}

${ }^{1} \mathrm{H}$ and ${ }^{13} \mathrm{C}$ nuclear magnetic resonance (NMR) spectra were recorded on a Bruker DRX500 spectrometer in $\mathrm{CDCl}_{3}\left(500 \mathrm{MHz}\right.$ for ${ }^{1} \mathrm{H}$ and $126 \mathrm{MHz}$ for ${ }^{13} \mathrm{C}$ ) using tetramethylsilane (TMS) as internal standard. Melting points were recorded in open capillary on an electrothermal apparatus (model Fisatom 430). The compounds were analyzed with Fourier transform model Shimadzu Prestige 21 (Shimadzu) scanning from 4000 to $600 \mathrm{~cm}^{-1}$ with a resolution of $4 \mathrm{~cm}^{-1}$. All solvents and chemicals were research grade and were used as obtained from Sigma-Aldrich (St. Louis, MO, USA).

\section{General procedure for the synthesis of thiocarbamoylpyrazoles}

In a $50 \mathrm{~mL}$ rounded flask, chalcone $\mathbf{1 a}-\mathbf{1 h}(2.0 \mathrm{mmol})$ and thiosemicarbazide $(2.0 \mathrm{mmol})$ were mixed with ethanol $(10 \mathrm{~mL})$ and $\mathrm{KOH}$ was added.22 The reaction mixtures were then inserted in a microwave model Discover System (CEM), with power $100 \mathrm{~W}, 250 \mathrm{psi}$ at $50^{\circ} \mathrm{C}$ for $15 \mathrm{~min}$. For the conventional methodology, the reagents were used at the same quantities and the reaction was refluxed for $4 \mathrm{~h}$. In both cases the solid obtained were filtered and washed with cold ethanol and dried under vacuum to give the pure 1-thiocarbamoyl-4,5-dihydro-1H-pyrazoles $\mathbf{2 a - 2 h}$. All compounds were macerated with liquid nitrogen for application as a powder.

\section{Latent fingermarks deposition and development}

Latent fingermarks were collected from 3 donors on glass surface and natural and sebaceous contents were evaluated. For sebaceous collection, the fingers were rubbed on nose and forehead and homogenized with each other, while for natural collection the donor's hand was washed with soap and water and the latent fingermarks were collected half an hour later. ${ }^{23}$ All the revelations were made $24 \mathrm{~h}$ after the depositions by physical method. Specific brushes were used for the development and cleaning of excess dust (132LBW and CFB100 from Sirchie ${ }^{\circledR}$ ). In addition, a Sirchie ${ }^{\circledR}$ fingerprint developer white powder was used as standard for comparison. The images were taken with a Canon EOS Rebel T6 semi-professional camera with a distance of $9 \mathrm{~cm}$ and focus 5.6.

\section{Results and Discussion}

According to the methodology used, a sequence of 1-thiocarbamoyl-3,5-diaryl-4,5-dihydro- $1 H$-pyrazoles was synthesized by thiosemicarbazide and the different substituted chalcones as shown in Scheme 1.

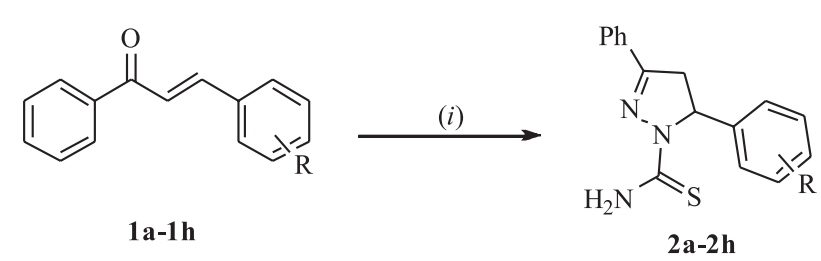

Scheme 1. (i) $\mathrm{NH}_{2} \mathrm{NHC}(\mathrm{S}) \mathrm{NH}_{2}, \mathrm{KOH}, \mathrm{EtOH}$, microwave, 15 min (yields $53-85 \%)$.

For optimization of the use of the best solvent in the synthesis of thiocarbamoylpyrazoles it was evaluated which of them had the best yield as shown in Figure 1. Optimization was performed using the unsubstituted structure 2a. From this, the best methodology was applied for the series of pyrazoles $\mathbf{2 a - 2 h}$.

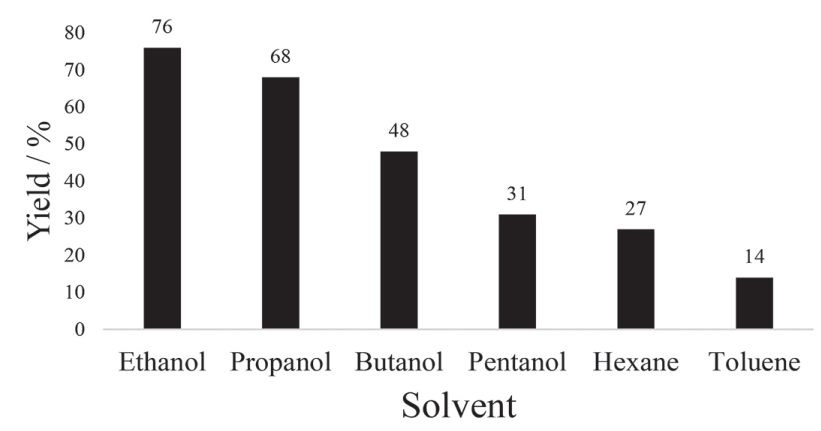

Figure 1. Solvent evaluation related to the yield obtained.

The compounds showed good yields (53-85\%) and high conversion (Table 1). These yields are in accordance with other methodologies ${ }^{24}$ such as utilization of ultrasound irradiation and more promising than conventional heating methodologies.

Moreover, the most satisfactory yield was obtained using ethanol, which also provided a synthesis process in accordance with green chemistry principles that include low cost and renewable materials. Such efficiency of ethanol to other solvents (Figure 1) may be related to the dielectric constant due to the greater dipole-dipole interaction necessary to cyclocondensation reaction and products obtention..$^{25} \mathrm{In}$ addition, the column purifications or recrystallization were not required, avoiding the excessive expenditure of solvents. 
Table 1. Preparation of 1-thiocarbamoyl-3,5-diaryl-4,5-dihydro- $1 H$-pyrazoles $\mathbf{2 a - 2 h}$ via microwave

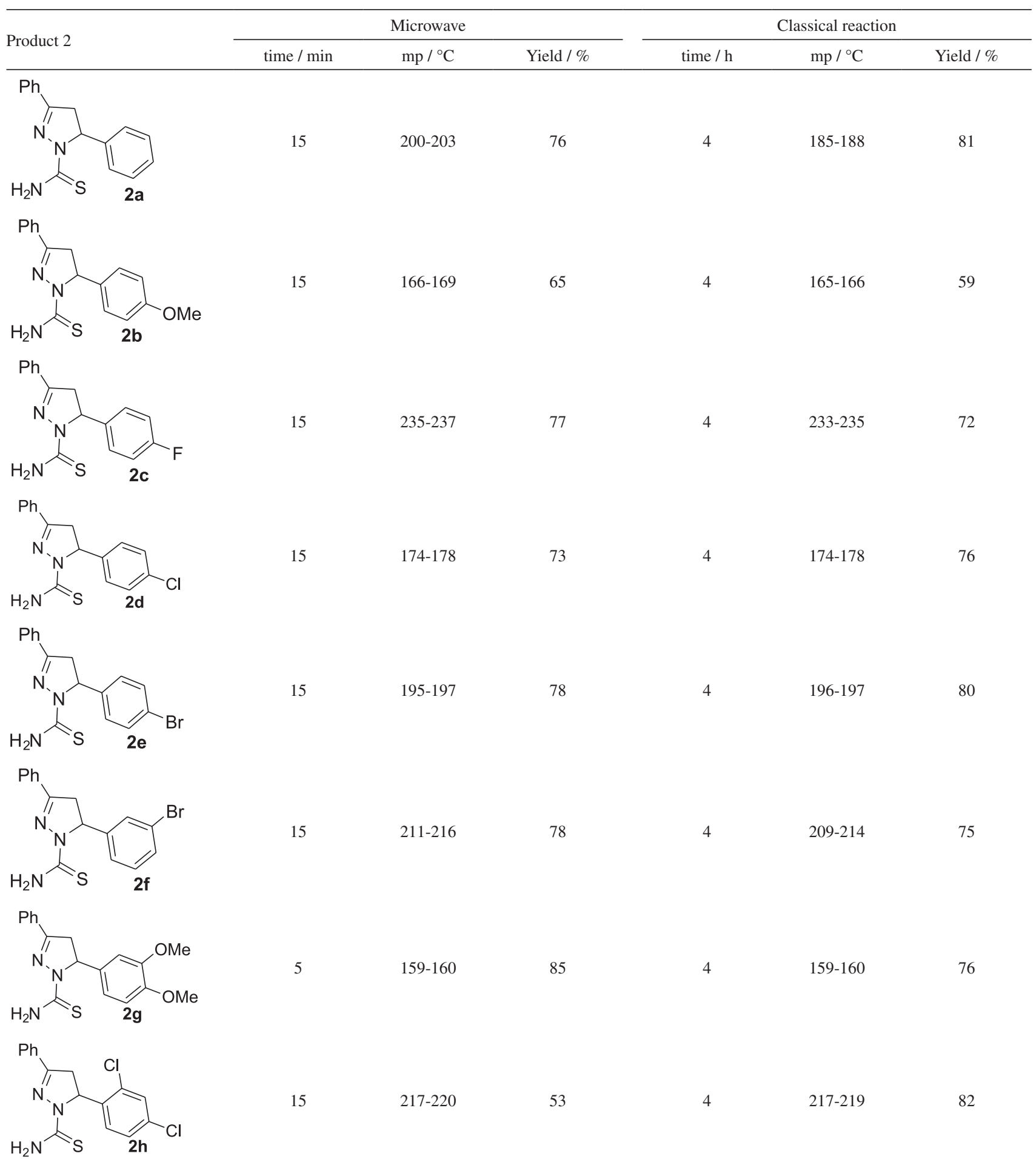

mp: melting point.

Moreover, the application of microwave irradiation avoided excessive reaction times and high temperatures.

The compounds $\mathbf{2 a - 2 h}$ were characterized by infrared spectroscopy (IR) and ${ }^{1} \mathrm{H}$ and ${ }^{13} \mathrm{C}$ NMR spectroscopy as described previously by our group. ${ }^{24}$ Spectroscopic data of the synthesized compounds are described in Supplementary Information section.

The prepared compounds $\mathbf{2 a - 2 h}$ were applied as latent fingerprinting powders and compared with commercial Sirchie $^{\circledast}$ white powder due to similar staining. In this 
sense, the evaluation of the image quality of fingermarks developments can be described by the level of detail according to Sears et al. ${ }^{23}$ where 0 corresponds to no mark evidence; 1 : weak development, evidence of contact but no ridge details; 2: limited development, about 1/3 of ridge details are present but probably cannot be used for identification purposes; 3: strong development, between $1 / 3$ and $2 / 3$ of ridge details, identifiable fingermark; 4: very strong development, full ridge details, identifiable fingermark. Thus, Table 2 shows the efficiency of the development of natural and sebaceous fingermarks using thiocarbamoylpyrazoles $\mathbf{2} \mathbf{a}-\mathbf{2 h}$ and the white standard powder.

From this, it was possible to identify that most of the compounds present efficiency similar or superior to the same color standard used by the scientific police. Molecule 2c provided promising results regarding image clarity resulting in visible ridges, strong development and presence of minutiae that assisted in the identification of fingermarks. ${ }^{26,27}$ In addition, to investigate the interaction of compounds with the surface, electron microscopy was performed. Figure 2 demonstrates a split assay in which the same fingermark was developed using compound $\mathbf{2 c}$ and the white standard powder. Moreover, Figure 2 also shows a scanning electron microcopy analysis of a fingermark enhanced with compound $\mathbf{2 c}$.

In special, from the comparison between compound $\mathbf{2 c}$ and the white standard powder it is possible to observe that both are similar, which confirms the efficiency of the new synthesized developer, providing good image quality. According to the SEM images, it is possible to observe the adhesion of the compound $\mathbf{2} \mathbf{c}$ to the glass surface. In addition, it was observed that the synthesized powder adhered only to friction ridges avoiding adherence to the glass surface and, thus, provided adequate images of the enhanced fingerprints.

\section{Conclusions}

In conclusion, a new synthesis methodology was developed for the 1-thiocarbamoyl-3,5-diaryl-4,5-dihydro$1 H$-pyrazoles series by microwave irradiation. It has advantages over existing methods such as reaction time and it does not require solvent waste in column purification. This procedure represents a economic and environmentally friendly process for the synthesis of pyrazole derivatives. These compounds represent a new class of latent fingermark developers. They demonstrated high quality images, especially pyrazole $\mathbf{2 c}$, which proved to be the most promising in natural and sebaceous fingerprints. Thus, the prepared compounds are of paramount importance because they provide fingerprints that could be used in human identification, contributing to the forensic sciences.

\section{Supplementary Information}

Supplementary data of the synthesized compounds

Table 2. Developing efficiency of thiocarbamoylpyrazoles $\mathbf{2} \mathbf{a}-\mathbf{2} \mathbf{h}$ and white standard powder on sebaceous and natural fingermarks

\begin{tabular}{|c|c|c|c|c|c|c|c|c|c|c|}
\hline Thiocarban & azole $^{a}$ & $\mathbf{2 a}$ & $2 \mathbf{b}$ & $2 c$ & $2 d$ & $2 \mathrm{e}$ & $2 f$ & $2 g$ & $2 \mathbf{h}$ & $\begin{array}{c}\text { White standard } \\
\text { powder }\end{array}$ \\
\hline \multirow{2}{*}{ Efficiency } & sebaceous fingermark & 3 & 3 & 4 & 2 & 2 & 2 & 2 & 4 & 3 \\
\hline & natural fingermark & 2 & 2 & 4 & 2 & 1 & 1 & 2 & 3 & 3 \\
\hline
\end{tabular}

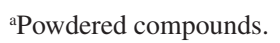

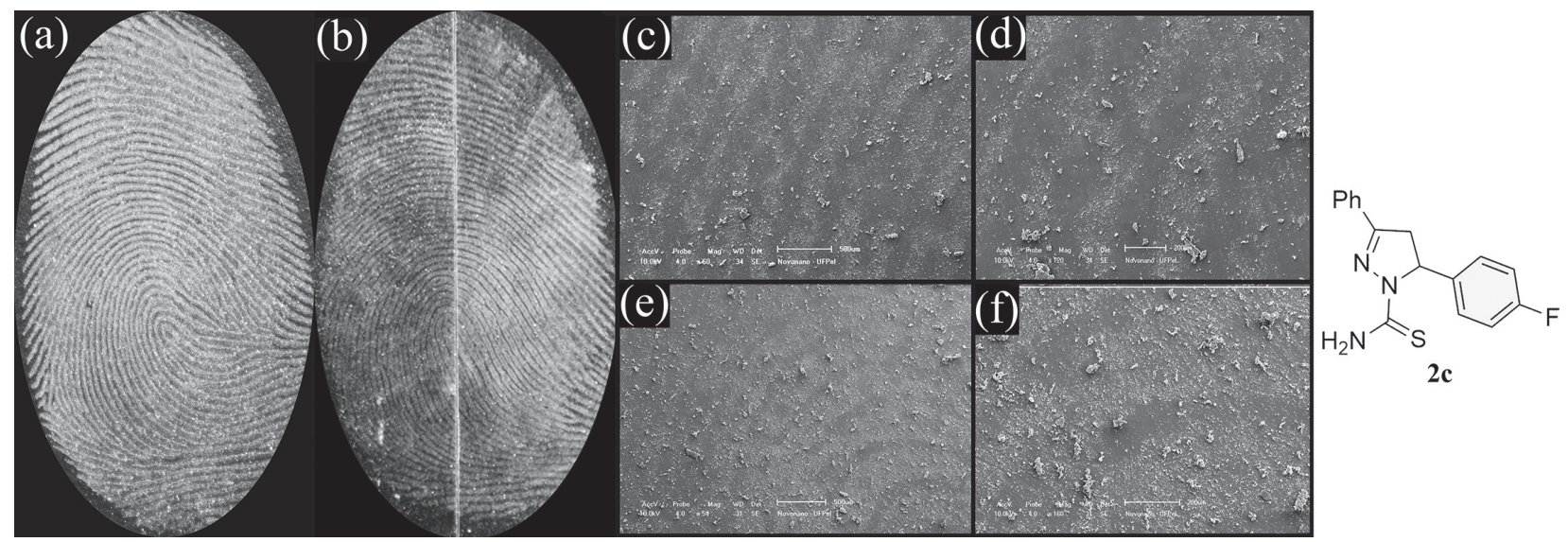

Figure 2. Latent fingermark developed using (a) pyrazole $2 \mathrm{c}$ and (b) white standard powder; SEM images with dimensions (c, e) 500 and (d, f) $200 \mu \mathrm{m}$ revealed with compound $\mathbf{2 c}$. 
2a-2h and fingerprint development analysis associated with this work are available free of charge at http://jbcs.sbq.org.br as a PDF file.

\section{Acknowledgments}

The authors are grateful to the Coordination for the Improvement of Personnel in Higher Education (CAPES) and National Institute of Science and Technology (INCT Forencics, CNPq 465450/2014-8) for technical assistance and resources. This work is part of the project "Revealers and Forensic Markers: Obtainment and Chemical Properties $-8634 "$

\section{Author Contributions}

Bruno N. da Rosa was responsible for the investigation and resources; Dalila Venzke for the writing review and editing; Taís Poletti, Nathalia P. K. de Lima and Jeanifer T. Camacho for the investigation; Kristiane C. Mariotti for the validation; Marco A. Z. dos Santos and Neftalí L. V. Carreño for the formal analysis; Lucas Pizzutti for the resources; Claudio M. P. Pereira for the project administration and resources.

\section{References}

1. Dias, D.; Pacheco, B. S.; Cunico, W.; Pizzuti, L.; Pereira, C. M. P.; Mini-Rev. Med. Chem. 2014, 14, 1078.

2. Weber, J.; Buss, J.; Rech, K.; Moraes, L.; Reisdorfer, F.; Pereira, C. M. P.; Collares, T.; Kömmling, F.; Biomed. Pharmacother. 2017, 94, 37.

3. Chandak, N.; Kumar, S.; Kumar, P.; Med. Chem. Res. 2013, 22, 5490.

4. Taher, A. T.; Mostafa, M. T.; Ali, N. R. E.; Hilmy, N.; Bioorg. Chem. 2019, 89, 103023.

5. Pizzuti, L.; Barschak, A. G.; Stefanello, F. M.; Farias, M. D.; Lencina, C.; Curr. Org. Chem. 2014, 18, 115.

6. Moghaddam, F. M.; Bardajee, G. R.; Ismaili, H.; J. Braz. Chem. Soc. 2007, 18, 1024.

7. Sangi, D. P.; Corrêa, A. G.; J. Braz. Chem. Soc. 2010, 21, 795.

8. Papernaya, L. K.; Shatrova, A. A.; Albanov, A. I.; Levkovskaya, G. G.; Rozentsveig, I. B.; Arkivoc 2016, 142.
9. Everson, N.; Loop, L.; Lazaro, H.; Belanger, B.; Koch, G.; Bach, J.; Manjunath, A.; Schioldager, R.; Law, J.; Grabenauer, M.; Eagon, S.; Tetrahedron Lett. 2019, 60, 72.

10. Chimenti, F.; Carradori, S.; Secci, D.; Bolasco, A.; Bizzarri, B.; Orallo, F.; Chimenti, P.; Granese, A.; Ya, M.; Eur. J. Med. Chem. 2010, 45, 800.

11. Michalski, S.; Shaler, R.; Dorman, F. L.; J. Forensic Sci. 2013, $58,215$.

12. Malik, A. H.; Kalita, A.; Iyer, P. K.; ACS Appl. Mater. Interfaces 2017, 9, 37501.

13. Cadd, S.; Islam, M.; Manson, P.; Bleay, S.; Sci. Justice 2015 , $55,219$.

14. Sharma, K. K.; Nagaraju, P.; Mohanty, M. E.; Baggi, T. R. R.; Rao, V. J.; J. Photochem. Photobiol., A 2018, 351, 253.

15. Barros, H. L.; Stefani, V.; Forensic Sci. Int. 2016, 263, 83.

16. Barros, H. L.; Stefani, V.; J. Photochem. Photobiol., A 2019, $368,137$.

17. Lee, J.; Joullié, M. M.; Tetrahedron Lett. 2015, 56, 3378.

18. Marminon, C.; Nacereddine, A.; Bouaziz, Z.; Nebois, P.; Jose, J.; Le Borgne, M.; Tetrahedron Lett. 2015, 56, 1840.

19. Rosa, B. N.; Pacheco, B. S.; Pereira, C. M. P.; Nicolodi, C.; Mariotti, K. C.; Carreño, N. L. V.; Pizzuti, L.; Silva, A. C. A.; Silva, A. F.; Campos, V. F.; Giongo, J. L.; BR pat. BR1020180136151 2018.

20. Balsan, J. D.; Rosa, B. N.; Pereira, C. M. P.; Santos, C. M. M.; Quim. Nova 2019, 42, 845.

21. Conceição, L. D.; Pereira, C. M. P.; Forgie, A. H.; Leite, F. R. M.; Forensic Sci. Int. 2019, 297, 198.

22. Ritter, M.; Martins, R. M.; Rosa, S. A.; Malavolta, J. L.; Lund, R. G.; Flores, A. F. C.; Pereira, C. M. P.; J. Braz. Chem. Soc. 2015, 26, 1201.

23. Sears, V. G.; Bleay, S. M.; Bandey, H. L.; Bowman, V. J.; Sci. Justice 2012, 52, 145.

24. Pizzuti, L.; Piovesan, L. A.; Flores, A. F. C.; Quina, F. H.; Pereira, C. M. P.; Ultrason. Sonochem. 2009, 16, 728.

25. Maridevarmath, C. V.; Malimath, G. H.; J. Mol. Liq. 2017, 241, 845.

26. Joseph, A.; Antonio, A. C.; J. Forensic Identif. 2014, 174, 64.

27. Bécue, A.; Anal. Methods 2016, 8, 7983.

Submitted: October 22, 2019

Published online: January 30, 2020 